\title{
SPECTRUM OF OPPORTUNISTIC PULMONARY INFECTIONS OTHER THAN TUBERCULOSIS IN PATIENTS WITH HIV
}

Sunita Gajbhiye ${ }^{1}$, Sharmila Raut ${ }^{2}$.

1. Assistant Professor, Department Of Microbiology, Government Medical College, Nagpur

2. Professor, Department Of Microbiology, Government Medical College, Nagpur

\section{CORRESPONDING AUTHOR:}

Dr. Sunita .Gajbhiye, Oasis, 11, Anand Nagar, Atrey layout, Nagpur (Maharashtra)

Pin code 440022.

E-mail: sunitarajgaj@yahoo.com

ABSTRACT: This study was designed to document the prevalence of pulmonary infections other than tuberculosis in patients with HIV. The study includes 50 patients with HIV Infection whose sputum sample was evaluated for presence of bacteria other than Mycobacterium tuberculosis. These patients were admitted in Tuberculosis and Chest diseases Ward for Pulmonary Tuberculosis. Both the expectorated and induced sputum samples were collected and processed for presence of bacterial and fungal pathogens including Pneumocystis carinii. From 50 HIV +ve cases with Lower Respiratory Tract infection 45 pathogens were isolated. They were Streptococcus pneumoniae (4.4\%), Staphylococcus spp (24.4\%), Klebsiella pneumoniae (13.3\%), E-coli (8.8\%). Haemophilus influenzae (2.2\%). Polymicrobial isolation was observed. This could be probably related to low level of immunosuppression and low CD4 counts. Pure fungal growth indicated poor prognosis. No case of Pneumocystis carinii pneumonia was detected..

KEY WORDS: HIV, Tuberculosis, Opportunistic infection.

INTRODUCTION: With the advent of AIDS, opportunistic pulmonary infections associated with HIV are the most common and most serious presenting illnesses in our country ${ }^{1,2}$. HIV-TB co-infection is a severe problem worldwide, but especially of concern in India where background rates of Tuberculosis are highest.1,9 Reports of Lower Respiratory Tract Infections (L.R.T.T.) caused by Mycobacterium tuberculosis have been documented earlier, but those caused by other respiratory pathogens are rare. Hence the present study was undertaken to study the prevalence of respiratory pathogens in HIV positive patients other than Mycobacterium tuberculosis.

MATERIALS \& METHODS: The present study was undertaken in 50 HIV cases with Lower Respiratory Tract Infections admitted in Tuberculosis and Chest diseases ward during one year period. In patients who were clinically and radiologically negative for pulmonary tuberculosis, an early morning expectorated sputum sample as well as induced sputum sample was collected in a sterile wide mouth container and transported immediately to the Microbiology Laboratory. Sputum samples were stained by Gram Stain and Ziehl- Neelsen Stain after confirming that the sputum samples were satisfactory. Induced sputum samples were processed for presence of Pneumocystis carinii trophozoites and cysts. Giemsa stain was also performed for presence of Pneumocystis 
carinii. The sputum samples were inoculated on Blood Agar, Chocolate Agar and Mac Conkey's Agar for bacterial pathogens and SDA (Sabouraud's Dextrose Agar) for fungal pathogens .The sputum samples were also inoculated on LJ media. However, none of the samples grew Mycobacterium tuberculosis. The other isolates obtained were characterized by their morphological and cultural characteristics and biochemical reactions as per standard techniques. ${ }^{3}$ Antimicrobial susceptibility testing were performed according to CLSI guidelines.

RESULTS/OBSERVATION: Out of 50 expectorated sputum samples processed, culture was positive in 43 cases and 2 cases showed contamination. The distribution of organisms according to their Gram character were as follows:

Table No. $1=45$

\begin{tabular}{|c|l|c|c|}
\hline S. No. & Morphology on gram stain & Number & $\mathbf{\%}$ \\
\hline 1) & Gram positive Cocci & 27 & $57.7 \%$ \\
\hline 2) & Gram negative coccobacilli & 1 & $2.2 \%$ \\
\hline 3) & Gram negative rods & 16 & $35.5 \%$ \\
\hline 4) & Gram positive budding yeast cells & 1 & $2.2 \%$ \\
\hline 5) & Gram positive thick bacilli & 2 & $4.4 \%$ \\
\hline & & 45 & \\
\hline
\end{tabular}

Table No. 2 Shows distribution of pathogens in 43 expectorated sputum samples

\begin{tabular}{|c|l|c|c|}
\hline S. No. & \multicolumn{1}{|c|}{ Bacterial Isolate } & Number & $\%$ \\
\hline 1$)$ & Streptococcus pyogenes & 11 & $25 \%$ \\
\hline 2 ) & Streptococcus Pneumoniae & 2 & $4.4 \%$ \\
\hline 3$)$ & Streptococcus viridans & 3 & $6.8 \%$ \\
\hline 4$)$ & Coagulase (+) ve staphylococci & 5 & $11.3 \%$ \\
\hline 5$)$ & Coagulase (-) ve staphylococci & 6 & $12.2 \%$ \\
\hline 6$)$ & Haemophilus influenzae & 6 & $2.2 \%$ \\
\hline 7$)$ & Klebsiella pneumoniae & 4 & $12.2 \%$ \\
\hline 8$)$ & E. Coli & 3 & $9.9 \%$ \\
\hline 9$)$ & Pseudomonas aeruginosa & 1 & $6.8 \%$ \\
\hline 10$)$ & Citrobacter freundii & 1 & $2.2 \%$ \\
\hline 11$)$ & Enterobacter aerogenes & 1 & $2.2 \%$ \\
\hline 12$)$ & Candida albicans & & $2.2 \%$ \\
\hline
\end{tabular}

DISCUSSION: The importance of respiratory infection in AIDS patients is well documented. As per figures from NACO, the common organisms encountered in Pulmonary infections in HIV positive patients were Mycobacterium tuberculosis and Pneumocystis carinii.5,12 In this study emphasis was given on respiratory infections other than tuberculosis. Induced sputum samples were processed for presence of Pneumocystis carinii. Induced sputum with $28.55 \%$ sensitivity for PCP can be used as an alternative to invasive BAL to diagnose PCP13. In the Indian context, PCP can occur with other pulmonary infections including tuberculosis, cryptococcosis and CMV14.A diagnosis of PCP must be considered in patients with a diverse array of pulmonary clinical and radiological presentations. 
Pneumocystis carinii causes severe pneumonia in patients with HIV. Occurrence of PCP establishes the diagnosis of HIV and it is the most common AIDS defining illness in the developed world15.In India, very low rates 0.7 to $7 \%$ of PCP have been reported ${ }^{16,17}$. Some reasons for this could be predominance of other pulmonary diseases like tuberculosis and due to under diagnosis of incident cases.PCP occurs in patients with $\mathrm{CD}_{4}$ counts under 200 cells per $\mu \mathrm{l}^{6,17}$.In our study, we could not detect any case of Pneumocystis carinii pneumonia.

Pulmonary infections of fungal origin occur less commonly in immuno compromised patients and is attributed to low CD4 counts6,18. Fungal pathogens frequently coexist with other bacterial pathogens. In this study Candida albicans was associated with Staphylococcus aureus in 1 case. In one study by Ayyagari et al $1999^{19}$ found tuberculosis to be the commonest infection in HIV positive patients followed by candidiasis. In our study one case of candidiasis was isolated. The other bacterial pathogens which were isolated were less common in immunocompetent individuals. They included Citrobacter freundii and Enterobacter aerogenes. In the present study an attempt was made to demonstrate the presence of trophozoites/cysts of Pneumocystis carinii in induced sputum samples. However none of the samples were positive for Pneumocystis carinii Cysts or Trophozoites.

This study demonstrates that lower respiratory tract infections in HIV +ve patients caused by non-tubercular pathogens was significantly higher and included pathogens which were not routinely isolated is normal individuals with Lower Respiratory Tract infections.

Patients with AIDS are at increased risk for community acquired bacterial pneumonias. Such pneumonias should be included in the differential diagnosis of pulmonary infiltrates in this group. Because of the large number of potential pathogens an aggressive diagnostic approach to establish the specific etiologic diagnosis and implement appropriate therapy is warranted.

\section{REFERENCES:}

1. Solomon S., Kumaraswamy N., Anuradha S., Vennila B., Pal JA., T.B. \& HIV infection association Indian I. Medical Microbiology 1994, 12, 313-4.

2. Singh A. Bairy I Shivananda P.G. Spectrum of opportunistic infections in AIDS cases Indian J. Medical Science 2003, 57: 16-21.

3. Collee J.G, Fraser AG, Marmion BP, Simmons A. Mackie and McCartney Practical Medical Microbiology - 14th ed New York, Churchill Livingston 1999.

4. Bauer AW, Kirby WMM, Sherris JC, Turck M. Antibiotic susceptibility testing by a standardized single disk method. Am J Clin Pathol 1966; 45; 493-6

5. NACO-Epidemiology of HIV/AIDS Surveillance in Indian Spectrum of opportunistic infection in AIDS in India specialists Training and Reference Module. National AIDS Control Organisation. New Delhi 1999, 1-11, 12-17, 111-120.

6. Vajpayee M. Kanswal S., Seth P. Wig N. Spectrum of opportunistic Infections and profiles of CD cell counts among AIDS patients in Northern India Infection 2003, 31, 336-40.

7. Sharma S.K. Aggrawal G. Seth, P. Saha P.K. increasing HIV seropositivity among adult tuberculosis patients in Delhi. Indian J. of Medical Res. 2003, 117, 239-42.

8. Kumar P. Sharma N. Sharma N.C. Parnaik S. Clinical profile of tuberculosis in patients with HIV infection AIDS. Indian J. Chest Dis Allied Science 20021, 44, 159-63. 


\section{ORIGINAL ARTICLE}

9. Kumaraswamy N. and Solomon S. et.al. Spectrum of opportunistic infections among AIDS patients in Tamil Nadu. India Int. J. STD AIDS (1995) 6:447-9.

10. Whafen C.C. Horsburgh C.R. Hon D. Lahari C. Simberkoffr M. Effner J. Accelerated course of HIV infection after tuberculosis. Am J. Respir Crit case Medical 1995-151:129-35.

11. Sengupta D. Lal S. Shrinivas Opportunistic infection in AIDS J. Indian Medical Association. 1994: 92:24-6.

12. Stover D.E. White D.A. Romano P.A. et.al. Spectrum of pulmonary diseases associated with the acquired immune deficiency syndrome. Am. J.Med. 1985:78, 429-37.

13. Usha MM, Rajendra P, Thyagarajan SP, Solomon S, Kumaraswamy N, Yepthomi $T$ et al. Identification of Pneumocystis carinii in induced sputum in AIDS patients in Chennai(Madras). Indian J Pathol Microbiol 2000;43:291-6

14. Deshmukh SD, Ghaisas MV, Rane SR, Bapat VM, Pneumocystis carinii pneumonia and its association with other opportunistic infections in AIDS - An autopsy report of five cases. Indian J Pathol Microbiol 2003;46:207-11

15. Jones JL, Hanson DL, Dworkin MS , Alderton DL, Fleming PL, Kaplan JE, Ward J. Surveillance for AIDS - Defining opportunistic illnesses,1992-1997 MMWR CDC Surveill Summ 1998; 48:1-22

16. Lanjewar DN, Duggal R. Pulmonary pathology in patients with AIDS :An autopsy study from Mumbai HIV Med 2001;2: 266-71

17. Kumaraswamy N, Solomon S, Flanigan TP , Hemalatha R, Thyagarajan SP, Mayer KH. Natural history Human Immuno Deficiency Virus disease in Southern India. Clin Inf Dis 2003; 36: 79-85.

18. J. Kishore and G. Chaudhary. Spectrum of opportunistic infections in Human Immuno deficiency Virus (HIV) infected cases in a tertiary care hospital. Indian J. of Med. Microbiology (1999) 17(2), 78-80.

19. A. Ayyagari, AK Sharma, KN Prasad, TN Dhole, J Kishore and G Chaudhary. Spectrum of opportunistic infections in Human Immunodeficiency Virus (HIV) Infected cases in a tertiary care hospital. Indian J Med Microbiol 1999; 17(2); 78-89. 